be addressed by clinical teams to improve adherence and clinical outcomes.

Table 1. Multivariate analysis. Factors associated to non-adherence behaviors of patients with rheumatic diseases.

\begin{tabular}{|l|c|c|}
\hline & OR (95\% CI) & $\begin{array}{c}\text { p- } \\
\text { value }\end{array}$ \\
\hline Age (1-year increment) & $1.00(0.98-1.02)$ & 0.984 \\
\hline Gender (female versus male) & $1.04(0.57-1.90)$ & 0.892 \\
\hline $\begin{array}{l}\text { Need of taking medication 3-4 times per day } \\
\text { (versus 1-2 times per day) }\end{array}$ & $1.40(0.74-2.66)$ & 0.306 \\
\hline Number of different medicines (1-unit increment) & $1.00(0.89-1.14)$ & 0.967 \\
\hline IEXPAC overall score (1-unit increment) & $1.04(0.90-1.21)$ & 0.581 \\
\hline BMQ overall score (1-unit increment) & $0.95(0.91-1.00)$ & 0.052 \\
\hline
\end{tabular}

Acknowledgement:

Funded by Merck Sharp \& Dohme of Spain and endorsed by 4 patients associations: ACCU, CONARTRITIS, SEISIDA, FEDE.

Disclosure of Interests: María L. García Vivar: None declared, Javier de Toro-Santos: None declared, Lucía Pantoja: None declared, Cristina Lerín Lozano: None declared, Silvia García-Díaz: None declared, Sabela Fernández Employee of: MSD, Yvonne Mestre Employee of: MSD, Lidia Feo-Lucas Employee of: MSD, Luis Cea-Calvo Employee of: MSD DOI: 10.1136/annrheumdis-2019-eular.2773

\section{THU0624 UNDERSTANDING ETHNIC DIFFERENCES IN THE UTILIZATION OF NONSTEROIDAL ANTI-INFLAMMATORY DRUGS FOR OSTEOARTHRITIS}

Ernest Vina ${ }^{1}$, Michael Hannon ${ }^{2}$, Jazmin Dagnino ${ }^{1}$, C. Kent Kwoh ${ }^{1} .{ }^{1}$ University of Arizona, Rheumatology, Tucson, United States of America; ${ }^{2}$ Pinney Associates, Pittsburgh, United States of America

Background: The prevalence of arthritis-attributable activity limitation, work limitation and severe pain are significantly higher among Hispanics than among non-Hispanic Whites (NHWs) in the US. While Hispanics are less likely to report regular use of nonsteroidal anti-inflammatory drugs (NSAIDs), reasons for this decreased NSAID use are unknown. It is also unclear whether there are ethnic differences in the use of both over-thecounter (OTC) and prescription NSAIDs.

Objectives: To determine: 1) if there are ethnic differences in the use of OTC and prescription oral NSAIDs for knee/hip osteoarthritis (OA); 2) if there are differences in familiarity with and perceptions of efficacy and risk of NSAIDs between Hispanics and NHWs; and 3) if patient attitudes/ beliefs about NSAIDs mediate observed ethnic differences in the use of NSAIDS for OA

Methods: Participants $\geq 50$ years of age with chronic frequent pain due to knee/hip OA completed structured interviews. Data on sociodemographic characteristics, clinical information, actual use of oral NSAIDs for OA treatment (last 6 months), and familiarity with NSAIDs (3 items, yes/ no response) were collected. Perceptions of efficacy (4 items) and risk (3 items) of NSAIDs were evaluated using five-category ordinal response scale questions. Responses were averaged, with higher values indicating higher perception of efficacy/risk. Fisher's exact or Wilcoxon-Mann-Whitney tests were conducted to determine if knowledge and perceptions about NSAIDs differed by ethnicity. Multivariable logistic regression models were built to determine if ethnic differences in NSAID use were mediated by knowledge and perceptions about the medication.

Results: Among knee/hip OA patients, Hispanics $(n=130)$, in comparison to NHWs $(n=204)$, were younger (mean age 61.8 vs. 65.7) and less likely to have an annual income of $\geq \$ 40 \mathrm{~K}(21.6 \%$ vs. $56.5 \%)$. Hispanics, compared to NHWs, had lower odds of using an OTC NSAID (OR 0.57, $95 \% \mathrm{Cl} 0.36-0.90$ ) but greater odds of using a prescription NSAID (OR 1.66, $95 \% \mathrm{Cl} 1.04-2.64$ ) for OA. Hispanics, compared to NHWs, were also less likely to ever hear about OTC and prescription oral NSAID to treat OA or have a good understanding of either oral NSAID type as a treatment for OA (Table 1). Mean [SD] perceived efficacy of OTC and prescription oral NSAIDs were slightly lower among Hispanics than NHWs (2.91 [0.98] vs. 3.12 [0.88], $\mathrm{p}=0.0565 ; 3.03$ [1.02] vs. 3.34 [0.87], $\mathrm{p}=0.0047$; respectively). Mean [SD] perceived risk of prescription NSAIDs was lower among Hispanics than NHWs (2.44 [1.03] vs. 2.82 [1.01], $\mathrm{p}=0.0012$ ). After adjustment for all familiarity with OTC NSAIDs questions, and perceived efficacy and risk of OTC oral NSAIDs scores, the association between OTC NSAID use and ethnicity was attenuated and no longer significant (OR $1.01,95 \% \mathrm{Cl}$ 0.54-1.89). After adjustment for familiarity with and perceptions of efficacy and risk of prescription NSAIDs, the association between prescription NSAID use and ethnicity remained signifcant (OR 2.62, 95\%Cl 1.51-4.54).

Conclusion: Among patients with knee or hip OA, Hispanics were less likely than NHWs to utilize an OTC oral NSAID as treatment for arthritis. They were also less familiar with the use of NSAIDs for OA treatment and less likely to believe in their efficacy. Patient familiarity and perceptions of OTC oral NSAIDs may mediate ethnic differences in the use of NSAIDs for knee/hip OA.

\begin{tabular}{|c|c|c|c|}
\hline & $\begin{array}{l}\text { Hispanics } \\
(\mathrm{n}=130)\end{array}$ & $\begin{array}{c}\text { NHWs } \\
(n=204)\end{array}$ & $p$-value* \\
\hline \multicolumn{4}{|l|}{ OTC NSAIDs, n (\%) } \\
\hline Heard About It & $100(78.13)$ & $192(95.05)$ & $<.0001$ \\
\hline Family/Friends Received It & $67(52.76)$ & 127 (62.25) & 0.1080 \\
\hline Have Good Understanding & $79(63.20)$ & $168(83.58)$ & $<.0001$ \\
\hline \multicolumn{4}{|l|}{ Prescription NSAIDs, n (\%) } \\
\hline Heard About It & $92(74.80 \%)$ & $173(85.22)$ & 0.0274 \\
\hline Family/Friends Received It & $56(45.16 \%)$ & $107(52.45)$ & 0.2120 \\
\hline Have Good Understanding & $78(62.90 \%)$ & $148(74.00)$ & 0.0462 \\
\hline
\end{tabular}

*Fisher's exact

Disclosure of Interests: Ernest Vina Grant/research support from: Astrazeneca, Consultant for: Astrazeneca, Michael Hannon Employee of: Pinney Associates, Jazmin Dagnino: None declared, C. Kent Kwoh Grant/ research support from: Abbvie, EMD Serono, Consultant for: Astellas, EMD Serono, Thusane, Express Scripts, Novartis

DOI: 10.1136/annrheumdis-2019-eular.4401

\section{THU0625 RHEUMATOLOGY IN A TEACHING HOSPITAL IN THE UK?}

Arani Vivekanantham, Zenab Sarwar Mateen, Roseanna Wheatley, Rachael Myers, Pippa Watson, Jayne Little. Manchester University NHS Foundation Trust, Manchester, United Kingdom

Background: Inpatient referrals to rheumatology vary nationally from paper/electronic methods to phone conversations with the rheumatology registrar. In our Trust, which includes two large teaching hospitals in the UK, rheumatology referrals were hand written, faxed to secretaries and then given to the rheumatology registrar. This method was time consuming and referrals often lacked vital information. The referrer would also not know when the registrar had received the referral. A quality improvement project (QIP) in another UK hospital has shown an electronic referral system to be more efficient and safer for patients [1]

Objectives: This QIP aimed to evaluate the current system for inpatient referrals to two rheumatology departments within one large UK NHS trust and to identify aspects for improvement

Methods: Two hundred and ten inpatient rheumatology referrals received between January 2018 - January 2019 were analysed retrospectively for inclusion of important information such as, patient location and referrer's contact details.

Results: The review of current referrals identified several areas for improvement. The results are summarised in Table 1. The reasons for referrals ranged from swollen, painful joints to new rashes and medication reviews.

Table 1. Inclusion of important items in inpatient rheumatology referrals

\begin{tabular}{lccc}
\hline Item & \multicolumn{3}{c}{$\begin{array}{c}\text { Inclusion of item in referral } \\
\mathbf{n}(\%)\end{array}$} \\
\cline { 2 - 4 } & $\begin{array}{l}\text { Wythenshawe } \\
\text { Hospital } \\
(\mathrm{n}=105)\end{array}$ & $\begin{array}{c}\text { Manchester Royal } \\
\text { Infirmary } \\
(\mathrm{n}=105)\end{array}$ & $\begin{array}{c}\text { Combined } \\
(\mathrm{n}=210)\end{array}$ \\
\hline Date of referral & $78(74)$ & $95(90)$ & $173(82)$ \\
Time of referral & $26(25)$ & $7(7)$ & $33(16)$ \\
Name of referrer & $102(97)$ & $92(88)$ & $194(92)$ \\
Referrer's contact details & $38(36)$ & $13(12)$ & $51(24)$ \\
Patient's name, hospital & $104(99)$ & $102(97)$ & $206(98)$ \\
number & & $101(96)$ & $196(93)$ \\
Patient location & $95(90)$ & $75(75)$ & $137(65)$ \\
Past medical history & $62(59)$ & &
\end{tabular}

A process mapping session was undertaken to identify how the referra system could be improved. An electronic referral system, via the loca electronic patient record (EPR), was created. As well as ensuring that there is an audit trail and referrals are received in a timely manner, referrers are provided with a proforma to direct them to supply the 